\title{
O DESAFIO DO ENSINO DE ENGENHARIA FRENTE AOS PROBLEMAS ECONÔMICOS, ENERGÉTICOS E A SUSTENTABILIDADE
}

\author{
THE CHALLENGE OF TEACHING ENGINEERING AHEAD TO ECONOMIC, ENERGY AND \\ SUSTAINABILITY PROBLEMS
}

\author{
Aline Fernanda Furtado
}

\begin{abstract}
RESUMO
O presente trabalho trata da formação de engenheiros no Brasil tendo em vista os novos desafios do século XXI. Com a modernização sofrida pelo país nos últimos vinte anos, novas exigências passaram a ser impostas aos perfis dos profissionais das áreas técnicas e adjacências. Tais exigências acabaram refletindo nas instituições de ensino tecnológico de nível superior, responsáveis por suprir a demanda de profissionais capacitados, especialmente engenheiros de diversas especialidades, requerendo habilidades como iniciativa, criatividade, liderança, autonomia e capacidade de solucionar problemas. Com este trabalho, através de entrevistas, foi possível investigar a situação atual do ensino de engenharia no Brasil, conhecer as opiniões e expectativas de estudantes e docentes, e discutir estratégias de ensino e a viabilidade de sua aplicação na sala de aula. Foi proposta, também, uma reflexão sobre o modelo curricular adotado pela maioria das instituições de ensino na área de engenharia pesquisadas, além de refletir sobre a capacitação do docente para formar engenheiro que o mercado de trabalho busca.
\end{abstract}

Palavras-chaves: Engenharia. Século XXI. Desafio. Sustentabilidade. Globalização. Mercado de trabalho. Estratégias de ensino. Currículo. Estudante. Docente.

\begin{abstract}
This paper deals with the training of engineers in Brazil in view of the new challenges of the XXI century. With modernization experienced by the country over the last twenty years, new requirements came to be imposed on profiles of professional technical and surrounding areas. Those requirements ended up reflecting on institutions of higher technological education level, responsible for supplying the demand for trained professionals, especially engineers of various specialties, requiring skills such as initiative, creativity, leadership, autonomy and ability to solve problems. With this work, through interviews, it was possible to investigate the current state of engineering education in Brazil, the views and expectations of students and teachers and discuss teaching strategies and the feasibility of its application in the classroom. A reflection on the curriculum model adopted by most educational institutions in the area surveyed engineering in addition to reflecting on the training of teachers to form the engineer that the labor market search..
\end{abstract}

Keywords: Engineering. XXI Century. Challenge. Sustainability. Globalization. Labor market. Teaching strategies. Curriculum. Student. Teacher. 


\section{INTRODUÇÃO}

$\mathrm{N}$

os últimos vinte anos o progresso científico e tecnológico rompeu a fronteira dos chamados países de primeiro mundo e alcançou o Brasil. Este, por sua vez, mais como consumidor do que como produtor de inovações tecnológicas. E com o estreitamento das relações comerciais internacionais advindas da globalização, o setor industrial brasileiro precisou se modernizar para acompanhar o ritmo dos novos hábitos de consumo da população. Com a modernização, novas exigências passaram a ser impostas aos perfis dos profissionais das áreas técnicas e adjacências. Tais exigências acabaram refletindo nas instituições de ensino tecnológico de nível superior, responsáveis por suprir a demanda de profissionais capacitados, especialmente engenheiros de diversas especialidades, requerendo habilidades como iniciativa, criatividade, liderança, autonomia e capacidade de solucionar problemas (QUADRADO, 2008).

Segundo o censo de 2010 do MEC/INEP o crescimento dos cursos tecnológicos aponta no sentido dos investimentos na educação profissional de nível superior, principalmente pela iniciativa privada, mas também pela expansão das Instituições Federais de Educação, Ciência e Tecnologia. O número de matrículas nas IFES (Instituições Federais de Educação Superior) em cursos tecnológicos aumentou 481\% de 2001 para 2010. Do total de 63.481 matrículas em cursos tecnológicos das IES (Instituições de Ensino Superior) no ano de 2010, 47.439 estão nos Institutos Federais. Para os cursos tecnológicos de Instituições Federais de Educação Superior, as áreas de engenharia e profissões de engenharia (cursos gerais), encontram-se apenas com 7,7\% de participação no total de matrículas e eletrônica e automação, com 6,2\%. A pequena procura por cursos na área de Engenharia e tecnologia afeta diretamente à demanda crescente do mercado por profissionais com este perfil, criando um grande número de vagas ociosas.

Além da baixa procura por cursos de ensino superior na área de Engenharia - se comparada à procura pelos cursos das chamadas ciências humanas - o alto índice de evasão nesses cursos também é um problema que as IFES têm que enfrentar. A evasão em sua maioria se deve, entre outros, à falta de pré-requisitos em disciplinas básicas como Matemática e Física, métodos de ensino ultrapassados, ao fato de parte do corpo docente apresentar uma metodologia e didática pouco apropriadas, inexistindo contextualização efetiva entre teoria e prática motivadoras aos estudantes.

É fundamental garantir o atendimento das demandas de formação inicial e continuada de trabalhadores, de educação profissional técnica de nível médio e de educação profissional tecnológica, de graduação e pós-graduação. A oferta de uma educação básica de qualidade, desenvolvida de forma articulada às modalidades acima mencionadas, representa um importante desafio. Outros problemas da educação profissional e tecnológica enquadram-se na prospecção 
adequada da demanda por educação técnica e tecnológica, na flexibilização da oferta de educação técnica e tecnológica e no reconhecimento de competências dos trabalhadores (MAPA ESTRATÉGICO DA INDÚSTRIA 2007-2015, p. 33).

Além disso, o modelo formal de ensino nos cursos de engenharia, baseado na lógica formal revela-se insuficiente, estabelecendo-se uma crise metodológica nas Universidades.

A lógica formal ao excluir as contradições como um equívoco do pensamento, a ser repelido a todo custo, condena-se a ser a lógica da superfície da realidade, da imobilidade das coisas, da intemporalidade dos fenômenos. Não é preciso esforço para se ver que essa concepção restritiva e unilateral significa falsear a objetividade, pois o mundo oferece uma dimensão infinita de profundidade, está em constante mobilidade e todos os fatos que nele ocorrem acham-se situados no tempo físico [...] a lógica formal não pode romper o círculo por ela mesma criado porque não tem poder para explicar a totalidade do conhecimento (Vieira Pinto apud ANASTASIOU, 2012 p. 25).

Outra importante questão a ser levantada diz respeito ao currículo dos cursos de Engenharia no Brasil. Será que o ensino curricular cumpre realmente a tarefa de formação ansiada pelos estudantes e, principalmente, pelo mercado deste tipo de carreira? Ou como diria Anastasiou (2012):

A organização acadêmica é feita por faculdades, por objetos de estudo, dos quais decorrem
os conjuntos de disciplinas rigidamente determinados. Os cursos seorganizam com um
período básico e outro profissionalizante, separando a teoria - que necessariamente vem
antes - da prática. Assim, os estágios ficam alocados no final do currículo escolar de cada
curso. [...] Por esses elementos, pode-se verificar que vários currículos universitários atuais
seguem ainda a configuração em grade, proposta há dois séculos; conforme o modelo da
racionalidade separa a teoria da prática e distingue as disciplinas do básico e do
profissionalizante com um conjunto de pré-requisitos, requisitos e outros, com a
configuração de coleção. Agrupadas por ano ou semestre, as disciplinas são destinadas a
um docente, que fica responsável por uma parte do currículo; assim, individualmente,
organiza seu plano de ensino e trabalha sua disciplina independentemente das demais
(ANASTASIOU, 2012, p. 28).

No ano de 1976, o então Conselho Federal de Educação aprovou a resolução n. ${ }^{\circ}$ 48/76, do Ministério da Educação, que estabeleceu uma nova forma de organização dos cursos, em grandes áreas, admitia habilitações ou ênfases nos cursos e definia o currículo mínimo com cargas-horárias preestabelecidas. Essa resolução teve um caráter extremamente avançado para a época e estabeleceu a inclusão de temas e tópicos nos currículos para além da formação puramente técnica do engenheiro. Essa resolução ficou em vigência por mais de três décadas. Apesar de ter sido revogada em 2002 pela aprovação da resolução CNE/CES n. ' 11/2002, do Conselho Nacional de Educação / Câmara de Educação Superior (CNE/CES) do Ministério da Educação, que estabelece as atuais diretrizes curriculares para os cursos de Engenharia, muitos autores acreditam que as práticas emanadas dessa resolução ainda prevalecem na maioria dos cursos de engenharia no país. 
As atuais Diretrizes Curriculares diferem essencialmente da resolução 48/76, principalmente pela flexibilidade e liberdade das instituições para construção dos currículos; pela mudança de concepção de currículo, de uma grade de disciplinas, baseada em conteúdos para o desenvolvimento de competências e habilidades que vão além da formação técnica; pela motivação de uma atuação mais ativa do aluno no processo de formação, entre outras. Essas Diretrizes Curriculares ainda estão sendo implantadas pelas instituições de ensino de engenharia, que, às vezes, têm encontrado resistência de muitos professores para mudar suas velhas práticas de ensinar. Além disso, o desenvolvimento de competências exige dos professores o emprego de novas metodologias de ensino-aprendizagem e de avaliação, nem sempre compreendidas por estes professores - mais por falhas na sua formação como educador do que pela disposição em inovar em suas atividades docentes (CORDEIROA et al., 2008).

No entanto, a formação de um bom engenheiro depende de outros fatores que fazem parte do processo de formação mais amplo de cidadãos e se iniciam no ensino fundamental e médio. Esse é um grande desafio para o governo brasileiro que reflete na formação de engenheiros capazes de promover o desenvolvimento sustentável da sociedade.

Empresas de base tecnológica tais como a Vale, a Fiat e a Petrobras, têm buscado engenheiros com diversas formações e têm encontrado dificuldades nesta tarefa (CORDEIROA et al., 2008). Esses fatos evidenciam que o desenvolvimento do Brasil pode esbarrar em condições que necessitam de profissionais capacitados, que busquem soluções de engenharia mais efetivas para a população.

O setor industrial, por ser demandante direto de engenheiros e profissionais de áreas tecnológicas, precisa assumir uma posição efetiva nos programas de reforma de educação na área de engenharia, participando como proponente de novas idéias e como patrocinador das mudanças. Alguns exemplos de ações promovidas pelas entidades de representação industrial e pelas próprias indústrias em parceria com universidades podem orientar a ampliação de iniciativas que promovam o desenvolvimento científico e tecnológico do país (CAVALCANTE, 2005).

Outra questão relevante a este estudo é a questão da formação do professor universitário e sua preparação para efetivamente formar engenheiros eficientes e atuantes.

A formação do professor universitário tem sido entendida, por força da tradição e ratificada pela legislação, como atinente quase que exclusivamente aos saberes do conteúdo de ensino. Espera-se que o professor seja, cada vez mais, um especialista em sua área, tendo-se apropriado, com o concurso da pós-graduação stricto sensu, do conhecimento legitimado academicamente no seu campo científico. O domínio do conteúdo, por sua vez, deve ser alicerçado nas atividades de pesquisa que garantam a capacidade potencial de produção de conhecimento (CUNHA, 2006). 
De fato, no que diz respeito às Universidades, e também a muitas instituições isoladas de ensino superior, os cursos de pós-graduação tornaram-se a principal fonte de formação do professorado do ensino superior (CUNHA et al. 2011). A quase ausência da formação pedagógica para o professor do ensino superior vem delegar um peso muito grande ao papel da experiência na constituição da prática docente do profissional que atua nesse nível de ensino (CUNHA et al., 2011). Se, antes, a profissão de professor baseava-se no conhecimento objetivo, no conhecimento das disciplinas, em muito semelhantes às outras profissões, hoje, apenas dominar esse saber é insuficiente uma vez que o contexto da aprendizagem não é mais o mesmo. Resta aos pesquisadores da área de docência do ensino superior tentar encontrar estratégias para formar os docentes que, por sua vez, deverão também encontrar estratégias eficazes para formar os profissionais de engenharia.

\section{PAPÉIS DOS ENGENHEIROS FRENTE AOS DESAFIOS DO SÉCULO XXI}

Os principais desafios do século podem ser descritos como: sustentabilidade, população, água, comida, energia, saúde, ambiente, terrorismo, conflitos, mudanças climáticas, biodiversidade, entre outros.

Diante de tais desafios podemos listar uma série de habilidades esperadas dos profissionais de engenharia: i) tornar a energia solar rentável; ii) produzir energia nuclear segura; iii) desenvolver métodos para capturar gás carbônico, produzido pela queima de combustíveis fósseis, reduzindo assim o aquecimento global; iv) tornar a água potável acessível; v) restaurar e melhorar as infraestruturas urbanas preservando o meio ambiente; vi) desenvolver sistemas informáticos de saúde, para que os médicos disponham de registros biológicos de pacientes; dentre outros.

Para alcançar tal objetivo é necessário conhecer o processo educativo, a "receita” usada para se “fazer um engenheiro”. É fundamental criar uma nova geração de estudantes de engenharia, dando início a uma mudança de paradigmas desde o Ensino Médio até a Pós-graduação.

Segundo Quadrado (2008), o perfil esperado nada mais é do que um Engenheiro Inventor e Empreendedor. Sabendo-se que um inventor é uma pessoa que a partir da percepção das necessidades humanas é capaz de criar novos sistemas e ou processos capazes de atender demandas outrora negligenciadas. Um Engenheiro cria "um mundo que não existia”, oferecendo soluções aos problemas à medida que esses surgem ou à medida que surgem novas tecnologias que permitem gerar soluções antes inviáveis. Um empreendedor por sua vez é a pessoa capaz de transformar novas idéias em produtos ou serviços a serviço da sociedade, gerando riquezas por meio desses e assumindo as responsabilidades e os riscos inerentes de tal processo. 
A tecnologia e a inovação são os elementos-chave para um desenvolvimento econômico sustentável. A competição mundial hoje é a grande corrida pelo conhecimento, na qual o capital humano, também chamado de talento, torna-se o bem mais precioso.

A indústria está se transformando e, nesse contexto, os seus principais ativos deixam de ser máquinas e prédios e passam a ser bens intangíveis como o capital humano e a capacidade de executar processos e de inovar (CAVALCANTE, 2005).

O engenheiro do futuro necessita de conhecimento profundo de uma tecnologia, de conhecer e relacionar conteúdos, métodos, teorias ou outros aspectos do conhecimento tecnológico. Mas, também, de um processo educativo orientado para a sustentabilidade. Permanecer apenas na integração de vários temas seria manter a realidade atual não transformando o conhecimento tecnológico em uma perspectiva de mudança social. Os processos que podem economizar energia e recursos, diminuir poluição, aumentar produtividade com distribuição equitativa de renda e evitar desperdício de capital, passam pela educação e inovação tecnológica norteadas pela conservação ambiental (CASAGRANDE JR., 2001 apud CASSILHA et al., página 2).

Para análise segura do papel atual do profissional de engenharia, é interessante observar o desenvolvimento histórico dos cursos de engenharia no Brasil, bem como da própria engenharia enquanto prática produtiva. Pode-se dizer que foi a partir do século XIX, com o crescimento ferroviário que a engenharia teve seu grande crescimento no Brasil, mas até a revolução de 1930 as atividades técnicas eram tratadas ainda com certo preconceito. A construção do aparato formador do engenheiro no Brasil deu-se, em sua quase totalidade, após a primeira década do século XX, numa fase de grande efervescência no campo científico e tecnológico e na expansão e internacionalização da economia. Até a primeira metade dos anos 40 desenvolveu-se uma indústria tradicionalista, que se modificou bastante ao longo dos anos. Com o grande número de investimentos públicos em infraestrutura dos anos 70, propiciou-se a formação de um grande acervo técnico da empresa nacional no setor da engenharia, sendo criada uma importante atmosfera de formação do engenheiro, mesmo fora da escola, pela própria indústria através de treinamentos visando à capacitação da mão de obra.

É importante reconhecermos hoje a diferença existente entre um engenheiro formado nos anos 90 e um engenheiro formado há 30 ou 40 anos. Os problemas de engenharia quase sempre apresentam um grande número de soluções possíveis. Antigamente, o profissional otimizava suas soluções com uma forte contribuição pessoal: a experiência que lhe dava uma noção de grandeza. Hoje exige-se muito mais do engenheiro quando formula e quando resolve os seus problemas, sendo a matemática um importante aspecto metodológico (PONTE, 1996, p. 2). 
Segundo Danna (1996), a maioria dos profissionais conclui os cursos de engenharia com uma formação deficiente, principalmente nos aspectos práticos, pouco criativos e com deficiências específicas em conhecimentos gerenciais, administrativos, sociais e ambientais. Tais fatores afetam diretamente o grau de desenvolvimento do país, ainda segundo Danna (1996, p. 4-19) “a densidade de engenheiros em países desenvolvidos é de quatro a cinco vezes maiores que a nossa. Isso se explica pela predominância até recentemente, de indústrias tecnologicamente atrasadas, principalmente pela falta de competição e pelo modelo adotado de substituição de importações”. É necessário reverter este quadro, exigindo-se maior competência e eficácia do engenheiro para aplicar na prática os resultados dos avanços científicos e tecnológicos do século atual.

A globalização da economia e a atuação em blocos econômicos vêm desencadeando uma nova concorrência global. As novas descobertas são incorporadas com velocidades crescentes à produção de bens e serviços, acarretando uma interação maior das empresas com as instituições de ensino. A globalidade e a interdisciplinaridade da engenharia devem intensificar-se.

Para tanto, é necessário que o engenheiro tenha forte formação básica, capacidade de conceber e operar sistemas complexos, competência para usar recursos computacionais, softwares e estações de trabalho, além de pleno domínio sobre qualidade total, segurança do trabalho e preservação do meio ambiente, bem como compreensão de aspectos administrativos e legais (DANNA, 1996).

Ainda, segundo Danna (1996), deverão ser consolidados dois tipos de perfis para os engenheiros: de concepção e de execução (Engenheiro Industrial).

Precisa ser feita também uma correlação entre a formação do engenheiro e suas atribuições profissionais de forma que

\footnotetext{
A atribuição profissional deve ser função da competência profissional e não do diploma como ocorre hoje. $\mathrm{O}$ aspecto cartorial deve dar lugar à possibilidade de as atribuições profissionais serem ampliadas ou até diminuídas em função de aquisição ou perda de conhecimentos. Deve ser estimulada a melhoria do processo de formação, através da avaliação das instituições de ensino de Engenharia (DANNA, 1996, p.1).
}

Neste intuito, foram feitas algumas propostas no documento "Contribuição da Indústria para a Reforma da Educação Superior” do CNI no ano de 2003: i) criar condições para o compartilhamento de infra-estrutura técnica e laboratorial das universidades com as empresas; ii) estimular a criação de pré-incubadoras nos laboratórios de pesquisas das universidades e de incubadoras de empresas no interior dos campi universitários; iii) estimular a implantação de parques científicos e tecnológicos nos campi das universidades brasileiras, em parceria com os setores público e privado; iv) promover a atração de centros e laboratórios de pesquisas das empresas para os campi universitários ou para os parques científicos e tecnológicos, visando provocar processos sinérgicos de avanço do conhecimento, benéficos a ambas as partes. 


\section{AS OPERAÇÕES DO PENSAMENTO}

De acordo com Anastasiou (2012), quando nos debruçamos sobre qualquer aprendizado, para além da simples memorização, todos efetivamos várias operações de pensamento. Mas, muitas vezes, até por desconhecimento, não refletimos sobre os desafios contidos nas diversas atividades propostas aos alunos. Se tivermos a clareza da complexidade delas e a intencionalidade de desafiarmos progressivamente nossos alunos na direção da construção do pensamento cada vez mais complexo, integrativo e flexibilizado, será impossível prever até onde chegaremos com os processos de ensino aprendizagem.

Essas operações estão também presentes nas ações que operacionalizamos com os estudantes, nos três momentos propostos na metodologia dialética: mobilização, construção e elaboração da síntese do conhecimento, buscando o conhecimento da visão inicial ou sincrética, à efetivação da análise e à síntese qualitativamente superior.

Se ao analisarmos os objetivos dos programas de aprendizagem, considerarmos esses três momentos, estaremos contando com um importante suporte na definição das estratégias facilitadoras e desafiadoras do pensar e da consequente apropriação do conteúdo pelos estudantes.

Segundo Anastasiou (2012), as operações mentais são elementos que interferem nas novas formas de organizar o processo de ensinagem (ensino + aprendizagem). As resistências não estão presentes apenas nas instituições, na organização curricular e nos docentes; para o estudante, também se constitui novidade ter de alterar a forma memorizativa e a passividade do assistir a aulas, extremamente mais simples que o desafio de realizar operações mentais.

No entanto, a ação do estudante se efetivará a partir do direcionamento dado pelos professores ao processo, com a escolha e efetivação de diferentes estratégias, constituindo-se como responsabilidade coletiva. Essa escolha deve e pode ser objeto de reflexão na discussão do contrato de trabalho e no início de cada ano ou semestre letivo. Conhecer os comportamentos que dificultam os processos de pensamentos mais complexos também deve ser objeto de cuidado por parte dos docentes.

Analisando especificamente os cursos de engenharia, no Brasil, vemos a necessidade de aplicação de processos de pensamento mais eficazes, capazes de estimular em alunos e professores habilidades cognitivas como raciocínio rápido e exato. Segundo Rocha (1996), no ambiente atual de competitividade, a capacidade de aprendizagem contínua revela-se como fator crucial de competitividade. 


\section{O CONHECIMENTO E O SABER ESCOLAR CURRICULAR}

Se conhecer é o processo pelo qual o homem compreende o mundo, o conhecimento é um conjunto de enunciados, formalizados ou não, sobre o mundo, que o homem produz e dos quais necessita, não só para comunicar-se, mas também para sobreviver, sendo o ato de conhecer uma ação que se vincula ao individual e ao coletivo (BOMBASSARO,1992 apud ANASTASIOU, 2012, p. 54).

Segundo Anastasiou (2012), na visão de docentes universitários, o conhecimento a ser construído na sala de aula inclui a absorção de sinais, os signos e as percepções adquiridas cotidianamente. São elementos já existentes na base cognitiva a partir dos quais se constrói o novo, reelaborado, considerando as inter-relações que se estabelecem com o meio social, cultural e educativo, pela experiência, descoberta e/ou informação. É o resultado da investigação científica e de um processo de interação com a realidade observada e vivenciada.

Para construir o conhecimento em uma universidade, na interação de processos e produto, é considerado o que construímos, assimilamos e acomodamos, pela experiência e comparação do dado novo com o que já temos elaborado adquirido formal ou informalmente, espontaneamente ou com objetivos específicos. Daí a facilidade maior ao trabalhar o conhecimento que é sistematizado e reconstruído constantemente na prática pessoal e profissional.

Nas instituições de ensino, o saber escolar é o objeto de transferência e construção de sínteses progressivamente mais complexas, em grupos e ambientes definidos, integrando o conhecimento sistematizado com o conhecimento do estudante e visando ao aprofundamento da experiência e à produção e reconstrução do conhecimento. Constituindo-se em um processo que é resultado do confronto entre diferentes alternativas de compreensão e de concretização do mundo.

A partir desses elementos, percebe-se que uma organização curricular tanto pode estar privilegiando determinada visão de ciência como apresentando outra: numa organização curricular ordenada pela grade ou coleção.

Já numa organização curricular globalizada, a integração se dá pelo próprio desenho curricular. Mesmo que o docente pretenda apenas lidar com uma parte do conhecimento, terá dificuldades em não favorecer a interação, pois o Projeto Político Pedagógico já se organiza nessa outra forma. E no planejamento feito já se propuseram formas de articulação em eixos, áreas, atividades ou módulos curriculares. (ANASTASIOU, 2012)

Um modelo curricular globalizante adota diferentes formas de processar o conhecimento em parceria estabelecida entre alunos e professores envolvidos. O conhecimento, organizado sob a 
forma de saber escolar e traduzido no nível de assimilação dos sujeitos aprendizes, é assumido como:

\begin{abstract}
Trajetória sempre provisória de aproximação do real; é dinâmico, admite controvérsias e divergências, traz subjacente uma série de compromissos, interesses e alternativas que contestam sua condição de universalidade que discutem sua condição de objetividade, que criticam sua condição de neutralidade. É momento dinâmico, onde as várias opções, compromissos e interesses se manifestam nos modos de conceber e abordar o real: interação que envolve sujeito e mundo histórico, buscando-se a verdade, construindo o homem e o mundo, deixando as marcas da ação do homem sobre o mundo e do mundo sobre o homem (LEITE, 1994 apud ANASTASIOU, 2012, p. 57).
\end{abstract}

Anastasiou (2012), reafirma que, também na universidade, o saber escolar leva o universitário a um confronto, via aproximação - a mais atualizada possível -, com o quadro científico teórico prático da área estudada. Porém, o ponto de partida tanto para essa aproximação como para um confronto deve ser a prática social dos universitários envolvidos.

A extinção dos currículos mínimos pela Nova LDB e, posteriormente, as Novas Diretrizes Curriculares para o Ensino de Engenharia trouxeram uma grande abertura para que as mudanças pudessem ocorrer e ao mesmo tempo imputaram grande responsabilidade às instituições de definirem de forma clara o perfil do profissional que elas irão formar. Mais importante ainda é a exigência de que as instituições passassem a declarar, no chamado Projeto Pedagógico do Curso, quais os mecanismos utilizados para efetivar suas propostas. A exigência da apresentação do Projeto Pedagógico, ao invés de apenas uma grade curricular, foi um grande salto para que os currículos passassem a refletir de forma mais real sua exequibilidade, condizente com suas condições de infraestrutura e perfil do corpo docente e discente. (SALUM, 2005, apud CAVALCANTE, 2005, p. 54).

Contudo, o contínuo desenvolvimento tecnológico e as mudanças da sociedade exigem do ensino, particularmente em engenharia, mudanças além da simples alteração de grades curriculares, aquisição de equipamentos para laboratórios ou de bibliotecas atualizadas (CASSILHA et al., 2011).

É responsabilidade fundamental de um curso de engenharia a formação de uma personalidade capaz de adequadamente absorver, utilizar e produzir conhecimento técnicocientífico. É insuficiente e inconveniente abarrotar a cabeça dos estudantes com informação apenas, com a experiência dos fatos passados ou com as soluções específicas dos fatos de hoje, o que gera no estudante a falsa impressão de que já existem em algum lugar soluções prontas e acabadas para os problemas que enfrentamos; basta encontrá-los e aplicá-los. Uma grave consequência é a supressão da criatividade e o estabelecimento de um comportamento passivo e subserviente. Tem-se a figura do "engenheiro de manual", despreparado para o enfrentamento de situações inéditas (NOGUEIRA, 1996, p. 4). 
Um dos problemas que atinge a maioria das escolas de engenharia, segundo Kury et al. (ANO), é a estrutura das grades curriculares tradicionais, que reserva um espaço limitado para as diversas disciplinas aplicadas de engenharia. Isso torna particularmente complexa a inclusão das novas teorias e técnicas que surgem a cada dia sem comprometer o conteúdo "tradicional”. Segundo Vieira (1996), o currículo mínimo em vigor no Brasil dá margem a grande grau de flexibilidade na composição dos currículos plenos. Assim, a carência do hábito de uma reflexividade sustentada por bases teóricas deixa os docentes do ensino superior, mais suscetíveis aos modelos externos, capazes de imprimir projetos pedagógicos nem sempre explicitados e, muito menos, discutidos.

Pimenta e Anastasiou (2002, p. 143), já haviam chamado a atenção para essa condição dizendo que a "universidade reforça o trabalho solitário, extremamente individual e individualizado; o professor é deixado à sua própria sorte e, se for bastante prudente, evitará situações extremas nas quais fiquem patentes as falhas de seu desempenho”. Complementando essa perspectiva, afirmamos que o trabalho solitário do professor também protege a sua autoridade científica que, no imaginário social e do próprio docente, já lhe é atribuída pelo simples fato de ser reconhecido como professor. Quase numa perspectiva de ensaio e erro, eles atribuem valor às aprendizagens que realizam com seus próprios alunos: "Para mim, o aluno é um termômetro; eles é que me ajudam, com suas perguntas e reações, a ver o que está dando certo (CUNHA, 2006, p. 262).

Deparamo-nos, então, com duas questões cruciais: o conhecimento adquirido pelo próprio profissional de engenharia enquanto docente e o saber inerente aos currículos escolares. Resta-nos investigar as possibilidades apresentadas ao longo desse artigo buscando uma solução viável no sentido de melhorar a qualidade tanto de preparo dos professores universitários dos cursos de engenharia como um todo quanto dos currículos desses mesmos cursos.

\section{ESTRATÉGIAS DE ENSINAGEM}

A proposta discutida no livro "Processos de Ensinagem na Universidade” de Anastasiou e Alves (2012), situa o estudo e a análise das estratégias de ensino e de aprendizagem diretamente relacionados a uma série de determinantes: um Projeto Político Pedagógico Institucional em que se defina uma visão de homem e de profissional que se pretende possibilitar na educação superior; a função social da universidade; a visão de ensinar e de apreender; a visão de ciência, conhecimento e de objetivos interdisciplinares por meio de módulos, ações, eixos, problemas, projetos, entre outros. 
É nesse contexto que se constrói o trabalho docente, e que o professor se vê frente a frente com a necessidade e o desafio de organizá-lo e operacionalizá-lo. Também nesse contexto relacional que se inserem as estratégias de ensinagem.

Estratégia - do grego strategía e do latim strategia - é a arte de aplicar ou explorar os meios e condições favoráveis e disponíveis, com vistas à consecução de objetivos específicos. Portanto, exige-se por parte de quem a utiliza criatividade, percepção aguçada, vivência pessoal profunda e renovadora, além da capacidade de pôr em prática uma ideia valendo-se da faculdade de dominar o objeto trabalhado. O professor deverá ser um verdadeiro estrategista, o que justifica a adoção do termo estratégia, no sentido de estudar, selecionar, organizar e propor as melhores ferramentas facilitadoras para que os estudantes se apropriem do conhecimento.

Ainda segundo Anastasiou e Alves (2012), as estratégias visam à consecução de objetivos; portanto, há que ter clareza sobre aonde se pretende chegar naquele momento com o processo de ensinagem. Por isso, os objetivos que o norteiam devem estar claros para os sujeitos envolvidos professores e alunos - e estar presentes no contrato didático, registrado no Programa de Aprendizagem correspondente ao módulo, fase, curso etc.

Por meio das estratégias aplicam-se ou exploram-se meios, modos, jeitos e formas de evidenciar o pensamento, respeitando as condições favoráveis para executar ou fazer algo. Esses meios ou formas comportam determinadas dinâmicas, devendo considerar o movimento, as forças e o organismo em atividade (ANASTASIOU, 2012). Por isso, o conhecimento do estudante é essencial para a escolha da estratégia, com seu modo de ser, de agir, de estar, além de sua dinâmica pessoal.

Outra referência é a lógica do conteúdo: um conteúdo predominantemente factual exigirá uma estratégia diferente de um procedimental. Além da lógica própria, o momento vivenciado pelos estudantes é, também, fundamental: estratégias usadas na mobilização comportam elementos novos e diferentes de estratégias de elaboração da síntese do conhecimento.

Lidar com diferentes estratégias não é fácil: entre os docentes universitários existe um hábito de trabalho com predominância na exposição do conteúdo, em aulas expositivas ou palestras, uma estratégia funcional para a transmissão de conteúdos prontos, acabados e determinados. Foi assim que vivenciamos a universidade como alunos. A atual configuração curricular e a organização disciplinar (em grade), predominantemente conceitual, têm a palestra como principal forma de trabalho. E os próprios alunos esperam do professor a contínua exposição dos assuntos que serão aprendidos.

Caso tal obstáculo seja vencido, ele ainda se vê diante de novos desafios para atuar de forma diferente, tais como: lidar com questionamentos, dúvidas, inserções dos alunos, críticas, resultados 
incertos, respostas incompletas e perguntas inesperadas. O novo procedimento abrange, também, uma modificação na dinâmica da aula, o que inclui a organização espacial, com o rompimento da antiga disciplina estabelecida.

Ainda resta a incerteza quanto aos resultados: na estratégia da aula expositiva se garante a relação tempo/conteúdo com maior propriedade. Pode-se até dividir o número de tópicos a serem repassados pelo número de aulas ou palestras, e tem-se todo o “programa vencido”. Vencer o programa não é garantia de ensino ou de aprendizagem, nem de viabilização do profissional necessário à realidade dinâmica e contraditória. Assistir a aulas como se assiste a um programa de TV e dar aulas como se faz numa palestra não é mais suficiente: estamos buscando modos de - em parceria - fazer aulas (ANASTASIOU e ALVES, 2012 p. 38).

A maioria das universidades brasileiras ainda não encontrou um caminho adequado para viabilizar um tratamento interdisciplinar e dialético do conhecimento (ROCHA, 1996).

Segundo Rocha (1996), uma estratégia combinada envolvendo ensino e pesquisa é recomendável para a reconstrução dos programas de graduação e pós-graduação em engenharia no Brasil: a ampliação da pesquisa, com projetos interdisciplinares de relevância econômica e social em colaboração com grupos de outras áreas do conhecimento, processo educativo onde o estudante amplie seus interesses para além dos problemas clássicos da engenharia, desenvolvendo sua capacidade de aprendizagem e de trabalho em um ambiente capaz de evolução e de autoorganização.

As atividades de pesquisa precisam ser integradas ao processo educativo, como uma forma de abordagem do desconhecido, capacitando o educando a resolver problemas novos e a desenvolver plenamente sua criatividade. Isto não tem passado da retórica de docentes e pesquisadores, na tentativa de justificar os recursos investidos (ROCHA, 1996).

O desperdício de tempo com discursos (aulas) teóricos, que sequer serão memorizadas com alguma longevidade, precisa ser minimizado (ROCHA, 1996). Ênfase deve ser dada ao desenvolvimento de trabalhos em equipe.

Outro empecilho encontrado - a massificação do regime de tempo integral e dedicação exclusiva - em alguns departamentos universitários de engenharia, afastou a participação de engenheiros praticantes, formando gerações de docentes sem experiência (ROCHA, 1996).

Do ponto de vista qualitativo, é preciso fortalecer a integração do sistema educacional com o sistema empresarial, no sentido de dar aos cursos e à pesquisa nas Instituições de Ensino Superior (IES) um foco mais centrado nas necessidades da sociedade, das empresas e no desenvolvimento tecnológico e econômico do país (CORDEIROA et al., 2008). 
A educação em engenharia representa, então, um elemento chave nesse processo, já que a área de engenharia é uma atividade que, por excelência, é condutora da inovação na indústria e nos demais setores econômicos. Mas, se o engenheiro é sujeito ativo das transformações na era das mudanças tecnológicas rápidas, ele próprio vem sendo obrigado a promover profundas transformações em suas habilidades e em seu perfil profissional. A sociedade do conhecimento exige engenheiros com competências novas, com flexibilidade e autonomia para aprender permanentemente (CORDEIROA et al., 2008).

\section{METODOLOGIA}

Os métodos de pesquisa utilizados neste artigo foram basicamente estudos monográficos e de profundidade, incluindo a análise do maior número possível de variáveis que pudessem interferir no problema em questão.

Foram realizados levantamentos, sondagens e surveys, através de pesquisas de campo realizadas em instituições públicas de ensino superior em Engenharia: UFU, UFV e Cefet-MG; e privadas: UNIUBE, Uniaraxá e PUCMinas, nas modalidades presenciais e a distância, fazendo uso de questionários distribuídos aleatoriamente a estudantes e professores.

A análise dos dados coletados, tanto bibliograficamente quanto através da pesquisa de campo e entrevistas, foi feita de forma descritiva e explicativa. Finalizando-se com o levantamento de hipóteses aplicáveis.

\section{ANÁLISE DE DADOS}

Os dados coletados nas entrevistas foram analisados por meio de gráficos do tipo barra, coluna e pizza, como mostrado a seguir.

Os Gráficos 1 a 4 referem-se aos questionários respondidos pelos alunos dos cursos de engenharia participantes da pesquisa. Enquanto os gráficos 5 e 6 referem-se aos questionários respondidos por docentes da área de engenharia.

Em relação aos conteúdos que compõem as grades curriculares de seus cursos e a contribuição de tais disciplinas para a sua formação profissional, a maioria dos estudantes questionados os consideram suficientes. Mas uma parte dos estudantes entrevistados afirma que para uma boa formação profissional tais conteúdos precisam ser complementados com minicursos, estudos individuais, além de diversificadas atividades extraclasses. 
Gráfico 1 - Considerações dos estudantes entrevistados quanto aos conteúdos estudados

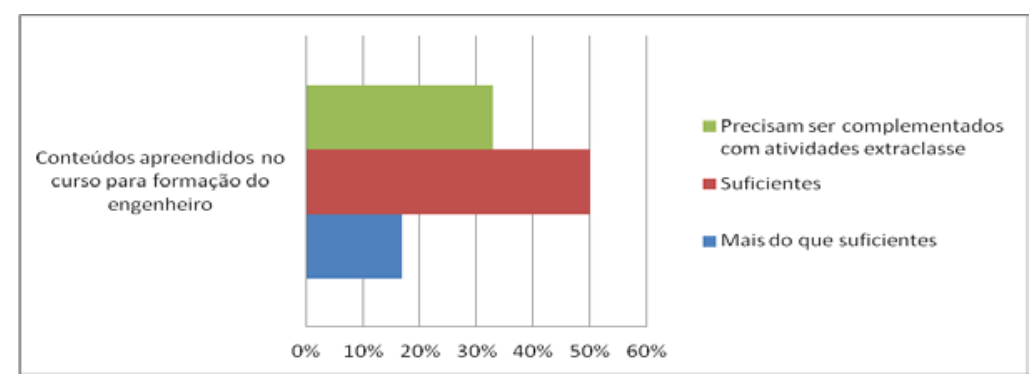

Fonte: Autoria própria

Foi observado que algumas poucas instituições de ensino, notadamente as instituições públicas, possibilitam um relacionamento entre os estudantes de engenharia e empresas, grandes e pequenas, de suas áreas de atuação através de programas de pesquisa e extensão, estágios, seminários e visitas.

Gráfico 2 - Relacionamento escola e empresa.

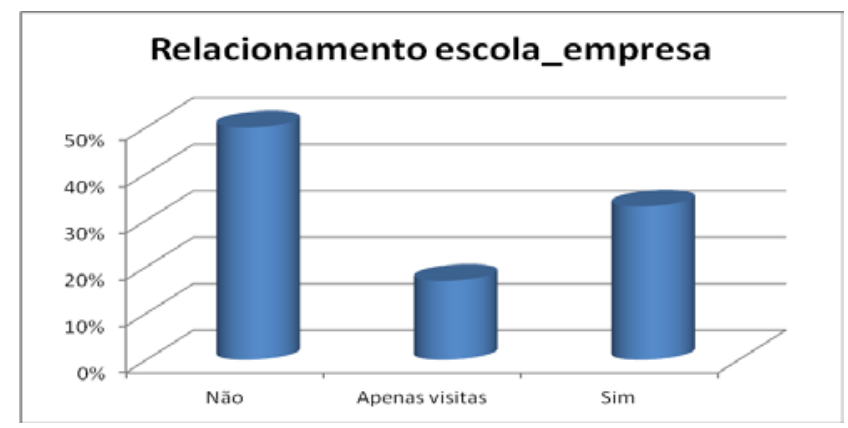

Fonte: Autoria própria

Quando questionados sobre seus cursos estarem preparando para os novos desafios do século XXI, globalização, sustentabilidade, entre outros, as opiniões dos estudantes foram bem divididas, mas a grande maioria dos estudantes concorda que tais objetivos só estão presentes em algumas disciplinas específicas relacionadas aos desafios sugeridos.

Gráfico 3 - Os conteúdos apreendidos x desafios do século XXI

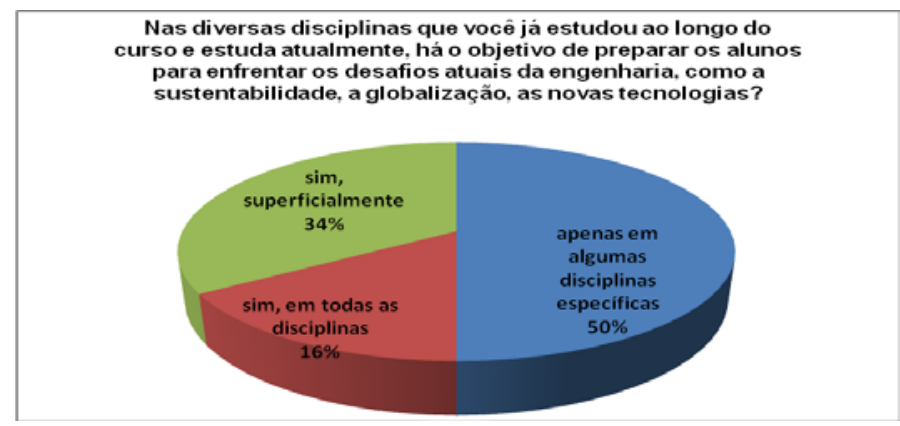

Fonte: Autoria própria

http://www.uftm.edu.br/revistaeletronica 
No gráfico 4, observa-se o sentimento dos alunos com relação ao preparo de seus professores. A grande maioria dos entrevistados concorda que suas instituições possuem ótimos docentes, mas que a maioria não está realmente preparada para transmitir os conhecimentos necessários à sua formação profissional, existe um grande número de professores que não possui didática, não conseguindo exteriorizar ao universo do aluno o conteúdo de forma clara e concisa.

Gráfico 4 - Considerações dos estudantes entrevistados sobre a formação dos professores

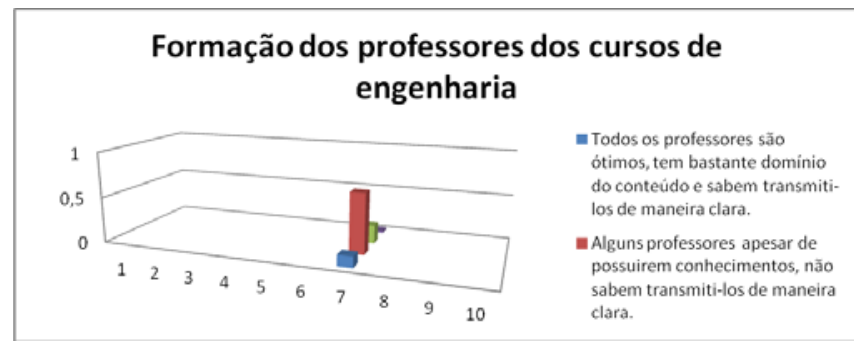

Fonte: Autoria própria

Interessante notar que o maior número de professores que respondeu ao questionário (distribuído igualmente entre as diversas instituições participantes da pesquisa) foram os docentes de instituições públicas.

Ao serem questionados sobre os pré-requisitos adotados nos cursos de engenharia das instituições em que trabalham, as opiniões ficaram bastante divididas, como se observa no gráfico 5.

Gráfico 5 - Considerações dos professores sobre os pré-requisitos

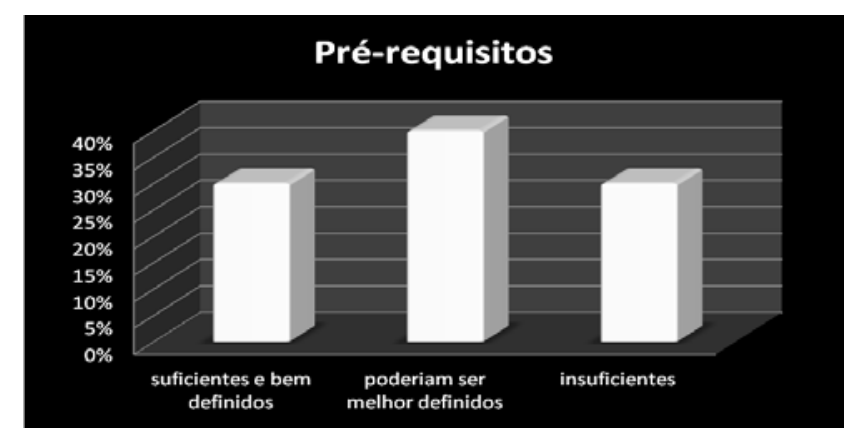

Fonte: Autoria própria

Quando perguntados sobre a complexidade dos currículos dos cursos de engenharia, 80\% dos docentes consideram a abordagem dos desafios da globalização, sustentabilidade entre outros, um tanto superficial, enquanto apenas $20 \%$ consideram-na suficiente.

No gráfico 6, temos a análise dos docentes de engenharia participantes da pesquisa quanto à formação didática específica recebida por eles. 
Gráfico 6 - Relato dos docentes sobre sua formação.

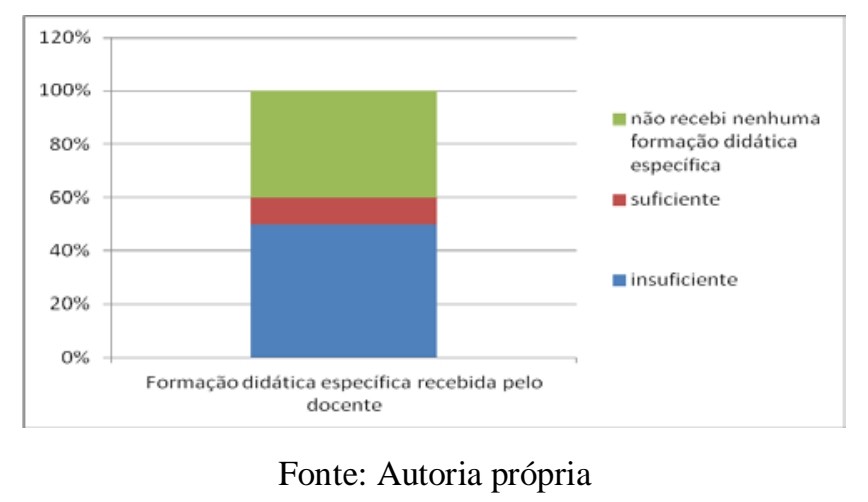

\section{Análise de resultados}

Dos estudantes entrevistados, 85\% têm entre 18 e 23 anos de idade e cursam engenharia em Universidades Particulares; 15\% são maiores de 23 anos; 15\% estudam em Universidades Públicas. Interessante observar que todos os estudantes de engenharia de instituições públicas estudam em regime integral, enquanto os estudantes das instituições privadas cursam período noturno.

Dos docentes entrevistados, $80 \%$ são doutores e 20\% mestres; 90\% lecionam há mais de 10 anos, enquanto os outros $10 \%$ lecionam entre 2 a 5 anos. A maioria desses professores trabalha com disciplinas teóricas e práticas. Todos os professores entrevistados (100\%), consideram muito importantes suas disciplinas para a formação dos profissionais em engenharia e, também, consideram as estratégias de ensino adotas em suas instituições suficientes.

Observando os gráficos anteriores, conclui-se que a maior parte dos alunos dos cursos de engenharia entrevistados não estão completamente satisfeitos com o desempenho de seus cursos no que se refere à sua formação como profissionais capacitados para enfrentar os novos desafios do século XXI.

Com relação à pesquisa realizada junto aos professores dos cursos de engenharia, alguns deles deram sugestões interessantes para a melhoria da qualidade da formação de profissionais nas instituições de ensino, uma delas seria a proposta de ampliar a carga horária, ou até mesmo criá-la onde inexistente, do estudo do processo de comunicação oral e escrito, proporcionando assim a aquisição de mais habilidade para a produção de textos escritos e até mesmo da comunicação dos futuros engenheiros. Há ainda outro grupo que defende uma proposta de interdisciplinaridade acompanhada pela sustentabilidade.

Houve um docente da UFU que chamou a atenção para a atual organização do sistema pelo MEC, na qual não há mais a obrigatoriedade dos pré-requisitos para um aluno cursar uma ou outra disciplina, avaliando tal procedimento nocivo tanto aos alunos quanto aos professores. Questionou- 
se, ainda, acerca de algumas exigências do MEC quanto à formação de mais engenheiros em menos tempo, ou seja, tem sido dado destaque à quantidade em detrimento da qualidade.

Houve ainda alguns docentes que colocaram em dúvida o perfil profissional do engenheiro que deve ser formado, afirmando que o próprio setor produtivo, muitas vezes, não define exatamente o tipo de profissional almejado, preferindo técnicos para desempenhar funções que poderiam ser realizadas por engenheiros, não se preocupando em investir na formação destes últimos e, na maioria dos casos, responsabiliza as instituições de ensino pela falta de mão de obra qualificada no mercado.

A maioria dos docentes entrevistados ressalta ainda que tiveram como formação base cursos na área de engenharia e não receberam nenhuma formação didática específica durante os cursos de mestrado; alguns docentes especializaram-se em educação e cursaram pedagogia por iniciativa própria, mas a maioria se formou realmente no dia a dia da sala de aula.

Embora alguns professores de engenharia entrevistados acreditem que se adequar às novas tecnologias disponíveis para o ensino (multimídias) seja o bastante para se aprimorar o ensino de engenharia para o século XXI, há quem discorde e afirme que apenas fazer uso de tecnologia seja uma estratégia insuficiente enquanto os alunos não adquirirem um hábito de estudo e responsabilidade por sua própria formação.

\section{CONSIDERAÇÕES FINAIS}

Classicamente, o engenheiro é visto como um técnico especializado na solução de problemas específicos e limitados a determinadas atividades ou campos de interesse (ROCHA, 1996). Hoje, precisam ser vistos como profissionais polivalentes aptos a contribuir para a solução de uma grande diversidade de problemas humanos, trabalhando em equipe e em temas interdisciplinares que envolvem a cooperação com outras categorias.

É preciso manter processos permanentes de acompanhamento e avaliação do ensino para poder rever e adaptar os currículos, questionando sobre o que está faltando, o que é desnecessário, sobre o que ensinar e como fazê-lo (ROCHA, 1996).

Os estudantes precisam ser vistos como seres responsáveis e conscientes de que o principal interessado na aprendizagem é ele próprio. Cada vez mais os indivíduos serão aceitos nos empregos pela sua capacidade de aprendizagem e menos pelo que dizem seus currículos. 


\section{REFERÊNCIAS}

ANAstasiou, L. G.; ALVES, L. P. (Org) Processos de Ensinagem na Universidade: pressupostos para as estratégias de trabalho em aula. 10 ed. Joinville: Editora Univille, 2012.

BRASIL. Instituto Nacional de Estudos e Pesquisas Educacionais Anísio Teixeira. CENSO DE EDUCAÇÃO SUPERIOR 2010. Disponível em: <portal.mec.gov.br> Acesso em: 04 de setembro de 2012.

BRASIL. CONFEDERAÇÃO NACIONAL DA INDÚSTRIA - CNI. Mapa estratégico da indústria. Brasília, 2004. Contribuição da indústria para a reforma da educação superior. Brasília, 2004. Disponível em: <www.cni.org.br/portal/lumis/> Acesso em: 04 de setembro de 2012.

BRASIL. Conselho Nacional de Educação. Câmara de Educação Superior. Resolução CNE/CES 11, de 11 de março de 2002. Disponível em: <http://portal.mec.gov.br/cne/arquivos/pdf/CES112002.pdf> Acesso em: 04 de setembro de 2012.

CASSILHA, A. C.; CASAGRANDE JUNIOR, E. F.; SILVA, M. C. Energia e o ensino da engenharia na Universidade Tecnológica Federal do Paraná - UTFPR: Desafios para se alcançar a sustentabilidade. 2011.

Disponível em: <revistas.utfpr.edu.br/pb/index.php/...ct/.../697> Acesso em: 04 de setembro de 2012.

CAVALCANTE, C. R. R. Educação e inovação: o papel e o desafio das engenharias na promoção do desenvolvimento industrial, científico e tecnológico. 2005. Disponível em: <seer.cgee.org.br/índex.php/parcerias.../261/255> Acesso em: 04 de setembro de 2012.

CORDEIROA, J. S; ALMEIDA, N. N; BORGES, M. N; DUTRAD, S. C; VALINOTEE, O. L; PRAVIAF, Z. M. C. Um futuro para a educação em engenharia no Brasil: desafios e oportunidades. Revista de Ensino de Engenharia, v. 27, n. 3, p. 69-82, Edição especial 2008.

Disponível em: <www.upf.br/seer/index.php/ree/article/view/559> Acesso em: 04 de setembro de 2012.

CUNHA, A. M. O.; BRITO, T. T. R.; CICILlinI, G. A. Dormi aluno (a)... Acordei professor (a): interfaces da formação para o exercício do ensino superior. 2011. Disponível em: <http://www.prograd.ufop.br/Downloads/Docencianoenssup/Dormi_aluno_acordei_professor.pdf> Acesso em: 04 de setembro de 2012.

DANNA, F. L. O Perfil do Engenheiro no Século XXI. Seminário "O Ensino da Engenharia para o Século XXI nos Países Amazônicos" UNESCO e UNAMAZ. Editora: UNAMAZ - Belém 1996 Registro: 62:37 / E59. Disponível em: < http://www.ufpa.br/unamaz/index_arquivos/Page5716.htm> Acesso em: 04 de setembro de 2012.

NOGUEIRA, V. P. Desafios Para o Ensino de Engenharia na Amazônia. Seminário "O Ensino da Engenharia para o Século XXI nos Países Amazônicos" UNESCO e UNAMAZ. Editora: UNAMAZ - Belém 1996 Registro: 62:37 / E59. Disponível em: <http://www.ufpa.br/unamaz/index_arquivos/Page5716.htm> Acesso em: 04 de setembro de 2012.

PONTE, M. X. Situação Atual e Perspectivas do Ensino de Engenharia no Brasil. Seminário "O Ensino da Engenharia para o Século XXI nos Países Amazônicos" UNESCO e UNAMAZ. Editora: 
UNAMAZ - Belém 1996 Registro: 62:37 / E59. Disponível em: $<$ http://www.ufpa.br/unamaz/index_arquivos/Page5716.htm> Acesso em: 04 de setembro de 2012.

QUADRADO, J. C. Educação em Engenharia. Mercado e desenvolvimento. COBENGE São Paulo, 10 de setembro de 2008. Disponível em: < $\underline{w w w . a b e n g e . o r g . b r / A r q u i v o s / 7 / 7 . p d f ~}>$ Acesso em: 04 de setembro de 2012.

ROCHA, I. Reengenheirando o Ensino de Engenharia no Brasil. Seminário "O Ensino da Engenharia para o Século XXI nos Países Amazônicos" UNESCO e UNAMAZ. Editora: UNAMAZ - Belém 1996 Registro: 62:37 / E59. Disponível em: <http://www.ufpa.br/unamaz/index_arquivos/Page5716.htm> Disponível em: 04 de setembro de 2012.

SALUM, M. J. G. Educação, engenharia e desenvolvimento. [S.l.: s.n.], 2005.

Disponível em: <www.cgee.org.br/arquivos/pe 21.pdf> Acesso em: 04 de setembro de 2012.

VIEIRA, R. C. C. O Conceito de Engenharia e Sua Correlação com o Ensino de Engenharia e a Profissão de Engenheiro: Breve Análise da Experiência Brasileira. Seminário "O Ensino da Engenharia para o Século XXI nos Países Amazônicos" UNESCO e UNAMAZ. Editora: UNAMAZ - Belém 1996 Registro: 62:37 / E59. Disponível em: <http://www.ufpa.br/unamaz/index_arquivos/Page5716.htm> Acesso em: 04 de setembro de 2012. 